\title{
Precedentes de la Arqueología de la Arquitectura en la historiografía artística: las investigaciones de Francisco M. a Tubino en el Alcázar de Sevilla (1885)
}

\author{
Precedents of Archaeology of the Architecture in art historiography: Francisco \\ M. a Tubino's studies in the Alcázar of Seville (1885)
}

\author{
Carmen de-Tena-Ramírez ${ }^{1}$ \\ Facultad de Geografía e Historia - Universidad de Sevilla
}

\begin{abstract}
RESUMEN
Con este artículo pretendemos contribuir a la conciliación entre los estudios de Historia del Arte y de Arqueología de la Arquitectura, disciplinas que frecuentemente se han visto enfrentadas debido, fundamentalmente, a desavenencias entre sus métodos de trabajo. Para ello, presentamos y estudiamos un caso concreto, el de los estudios arqueológicos y artísticos llevados a cabo por Francisco M. a Tubino en el Alcázar de Sevilla durante 1885. Estos trabajos fueron los primeros en realizarse en el conjunto monumental con un método de investigación analítico y sistemático, constituyendo un punto de inflexión en la historiografía artístico-arqueológica del siglo XIX. Consideramos que son fiel reflejo de una época en la cual los perfiles de historiador del arte y de arqueólogo no estaban tan definidos como en la actualidad, y que bien pueden ilustrarnos acerca de las ventajas que trae consigo la vinculación y coordinación entre los métodos arqueológicos y los histórico-artísticos.
\end{abstract}

Palabras clave: Francisco M.a Tubino; Alcázar de Sevilla; Patio del Yeso; Cuarto del Caracol; historiografía artística.

\begin{abstract}
With this paper we try to intend to contribute to the reconciliation with the studies about Art History and Archaeology of Architecture, often confronted because methodological differences. Therefore, we present the archaeologic and artistic studies undertaken by Francisco M.a Tubino in 1885 in the Alcázar of Seville. This work was the first been made supported by a methodological practice in this monumental site, and it marks a turning point about artistic and archaeologic historiography. Tubino's work is a reflection of a time when there wasn't any difference between the art historian and the archaeologist and it may illustrate about teamwork between archaeologic and historical artistic methodology.
\end{abstract}

Key words: Francisco M.a Tubino; Alcázar of Seville; Patio del Yeso; Cuarto del Caracol; art historiography.

Cómo citar este artículo / Citation

De-Tena-Ramírez, C. 2017: "Precedentes de la Arqueología de la Arquitectura en la historiografía artística: las investigaciones de Francisco M.a Tubino en el Alcázar de Sevilla (1885)", Arqueología de la Arquitectura, 14: e053. doi: http://dx.doi.org/10.3989/arq.arqt.2017.002

\section{Copyright}

(c) 2017 CSIC. Este es un artículo de acceso abierto distribuido bajo los términos de una licencia de uso y distribución Creative Commons Attribution (CC-by) España 3.0.

\footnotetext{
cdetena@us.es | ORCID iD: http://orcid.org/0000-0001-5460-0851
} 


\section{PRESENTACIÓN}

El incremento de las investigaciones en Arqueología de la Arquitectura (AA), ha generado un creciente interés por los estudios teóricos y epistemológicos acerca de esta disciplina. Buena parte de los mismos han sido abordados en confrontación con la estrecha vinculación existente entre la Historia del Arte (HA) y la AA, y las relaciones que en el ámbito profesional y académico se han ido entretejiendo en torno a estas, comprendiendo tanto sus divergencias como sus puntos en común (Pierotti y Quirós 2000; Azkarate 2002; Carrero 2008; Arce 2009; Boto y Martínez 2010; Caballero 2012; Moreno 2014).

La abundante bibliografía disponible y la calidad de las aportaciones que ya se han presentado sobre este particular, nos animan a no retomar las controversias que actualmente existen entre los historiadores del arte y los arqueólogos de la arquitectura. Controversias que son fundamentalmente de carácter metodológico, pero que en nuestra opinión ya han sido correctamente argumentadas. Contando con ello, estimamos que el debate generado entre HA y AA debe seguir avivándose, no tanto desde una óptica teórica, que también es fundamental, sino mediante el estudio de casos concretos. Consideramos necesario acrecentar la conciliación entre ambas disciplinas, posicionándonos a favor de las ventajas que en el ámbito académico y patrimonial proporcionaría vincular los estudios y métodos de la AA con los de la HA. Por esta razón, deseamos contribuir a esta iniciativa presentando un caso que bien puede servir para recordarnos la importancia de las investigaciones interdisciplinares, en las cuales, la ciencia arqueológica se complemente con los métodos y aportaciones de la HA, y viceversa.

Este fue el caso de las investigaciones llevadas a cabo por Francisco M. ${ }^{a}$ Tubino en el Alcázar de Sevilla, en las que supo combinar las técnicas arqueológicas más vanguardistas de su época con los tradicionales estudios histórico-artísticos. Estos trabajos resultan idóneos para conocer y comprender un periodo historiográfico en el que apenas existía diferencia entre las investigaciones arqueológicas y las de las bellas artes. Tampoco existe una clara definición en Tubino, pero el método de trabajo que empleó en sus estudios arqueológicos y artísticos del Alcázar de Sevilla, comparte similitudes con las actuales técnicas de la AA. No queremos caer en el reduccionismo y considerar la AA una mera trasposición de las técnicas estratigráficas a la construcción (Brogiolo 2002: 19); preferimos ampliar la concepción de esta disciplina, recordando a Mannoni cuando define la AA no como una ciencia completamente autónoma sino como una "tradición de estudios sobre arquitectura, basado no tanto en los estilos y cánones estéticos o en fuentes escritas e iconográficas de la arquitectura, cuanto en sus caracteres constructivos y en las transformaciones de los edificios" (cit. por Azkarate 2002: 13). Es en esta tradición de estudios y en su concepción epistemológica en la que estimamos oportuno emplazar a Francisco M. ${ }^{a}$ Tubino, considerándolo por ello un precursor de la AA.

\section{FRANCISCO M. a TUBINO Y LA ARQUEOLOGÍA ESPAÑOLA DEL SIGLO XIX}

Francisco M. ${ }^{a}$ Tubino y Oliva (San Roque, Cádiz, 1834 - Sevilla, 1888) fue un destacado arqueólogo, historiador y crítico de arte español de prolífica actividad. Comenzó su andadura profesional como periodista, siendo además literato, político, antropólogo y académico. Recuérdese que a finales del siglo XIX, los perfiles profesionales no estaban tan bien definidos como lo están ahora, donde la especialización es una constante en todas las ramas del saber. Hasta mediados del siglo XX, en España era habitual encontrar individuos tan polifacéticos como nuestro protagonista. Dado el amplio alcance de sus actividades profesionales, su figura ha sido parcialmente estudiada desde distintos enfoques (Gestoso 1889a; González-Deleito 1968; Muñoz 1988; Revuelta 1989; Arias 1990; Belén 1991; Rueda 1991; Ayarzagüena 1994; Acosta 1998; Belén 2002; Tubino 2003; Ayarzagüena 2004).

Aún teniendo muchas ocupaciones y todas de gran importancia, durante la mayor parte de su vida se mostró especialmente interesado por los estudios artísticos, así como por la incipiente ciencia arqueológica. Tubino fue un hombre de su época y al igual que ocurría con otros investigadores coetáneos, en él confluyeron los perfiles de arqueólogo de gabinete, al abrigo del estudio de las bellas artes, y el de campo, formado con especialistas procedentes de las ciencias naturales, de raigambre mucho más experimental.

Durante la segunda mitad del siglo XIX, la Arqueología y la Historia del Arte $-\mathrm{o}$ de las Bellas 
Artes-, convivieron formando parte de una misma materia de estudio. Las diferencias sustanciales que existen actualmente entre ambas no eran apreciadas entonces. Recordemos que tradicionalmente se ha considerado que Arqueología e Historia del Arte comparten un origen común en los estudios de Winckelmann (1717-1768). Este aspecto ha sido subrayado en numerosas ocasiones para recalcar que ambas surgen del mismo punto de partida, por lo que sus orígenes historiográficos son parejos (Ripoll y Ripoll 1988: 415; Díaz-Andreu 1995: 151; Moreno 2014: 3-4).

Desde mediados del siglo XIX, e incluso durante las primeras décadas del XX, y especialmente en España, la Arqueología fue considerada una ciencia que estudiaba las obras de arte y de la industria desde la óptica de su antigüedad (Peiró y Pasamar 1991: 146), precisando de grandes transformaciones hasta llegar a ser autónoma, en la década de 1920 (Díaz-Andreu 1995: 156). A este fructífero periodo de transición contribuyeron especialmente la adopción y puesta en práctica de métodos de investigación tomados de la Prehistoria (Bianchi Bandinelli 1982: 23), ciencia que durante la primera mitad del siglo XIX había permanecido en un discreto segundo plano. Igualmente sucedió con la Antropología, a la que era asimilada y con la que tuvo un desarrollo parejo. Estos nuevos estudios prehistóricos se fundamentaban en ciencias naturales como la Geología y la Paleontología (Ayarzagüena 1994: 401); de hecho, fueron naturalistas europeos de varios países los que contribuyeron a establecer la base instrumental definitiva para la Arqueología (Díaz-Andreu, Mora y Cortadella 2009: 27). Con la aplicación de estos nuevos métodos, los trabajos de campo pudieron perfeccionarse gracias a la introducción de las técnicas estratigráficas, hasta convertirse en herramienta principal para el arqueólogo, y en consecuencia, la Arqueología inició un camino divergente al que hasta entonces había seguido el estudio de las Bellas Artes (Díaz-Andreu 1995: 156).

Pero años antes de que la Arqueología española hubiera asumido los métodos de trabajo desarrollados y empleados en Prehistoria, algunos visionarios como Francisco M. ${ }^{a}$ Tubino, ya habían considerado su importancia; sabedor de su falta de conocimiento en la misma, decidió formarse convenientemente en sus técnicas y planteamientos. Para ello, asistió a las clases de Juan Vilanova y Piera en el Ateneo Científico y Literario de Madrid. Vilanova, sin duda el principal promotor de los estudios prehistóricos en España (Belén
2002: 48), fue un pilar importantísimo para la formación en Prehistoria de Tubino. Ambos compartieron su afán investigador y su interés por los orígenes del hombre, circunstancia que motivó que se convirtieran en compañeros de viaje en numerosas visitas y estancias en el extranjero. Juntos, recorrieron y visitaron los centros de investigación y las excavaciones prehistóricas más vanguardistas, aprehendiendo sus métodos con el fin de llevarlos a la práctica en el panorama español. De hecho, asistieron y participaron en el Congreso Internacional de Prehistoria de Inglaterra en $1868 \mathrm{y}$ al de Copenhague en 1869. También estuvieron en Suiza, Francia, Italia, Bélgica y Portugal.

Gracias al contacto con otros expertos, Vilanova y Tubino introdujeron y difundieron los métodos arqueológicos más avanzados que por entonces se desarrollaban en Europa, convirtiéndose en los principales difusores de la ciencia prehistórica en España desde finales de los años 60 del siglo XIX. Pero mientras que Vilanova tuvo un papel mucho más preponderante que Tubino en tareas de investigación prehistórica, las de este último fueron escasas, siendo su investigación más señalada la del descubrimiento-reconocimiento del dolmen de la Pastora en Valencina de la Concepción (Belén 1991: 10-15). Esta fue la principal aportación del autor a la historiografía de la arqueología prehistórica, sin menoscabo de la gran labor divulgativa que llevó a cabo (Ayarzagüena 1994: 42; Belén 2002: 43 y 44$)$.

Esta circunstancia no impidió que pudiera aplicar los métodos de estudio de la Prehistoria a otras investigaciones. Pero estas no se dirigieron hacia el trabajo de campo arqueológico que se entendía por entonces y hasta hace no pocos años, es decir, las tareas de excavación, sino que los métodos desarrollados por la Prehistoria, posteriormente asimilados por la Arqueología, los aplicó al estudio de la arquitectura histórica. Este planteamiento, que Tubino comparte con la AA, lo diferenció de la tradición de investigaciones sobre arquitectura histórica llevadas a cabo en España.

En conclusión, Francisco M. ${ }^{a}$ Tubino, después de haberse formado en la práctica de las técnicas empleadas por los investigadores en Prehistoria - fundamentalmente trabajos de campo inspirados en la Geología y en la anatomía comparada-, aplicó esos conocimientos a su afición por los estudios arqueológicos y artísticos, dando lugar a una serie de investigaciones que por sus objetivos, enfoque y método, podrían considerarse como precedentes para la AA. 


\section{HISTORIA DE LAS INVESTIGACIONES DE TUBINO EN EL ALCÁZAR DE SEVILLA ${ }^{2}$}

Francisco M. ${ }^{a}$ Tubino comenzó a investigar sobre el Alcázar de Sevilla a comienzos de la década de 1880, mientras trabajaba en uno de sus más estimados proyectos, la biografía de Pedro I de Castilla. Su intención era publicar un libro sobre el reinado de este monarca, cuyo título iba a ser Historia militar, política y diplomática del reinado de Pedro I. Desafortunadamente, esta obra no llegó a ver la luz, debido a su prematura muerte en el año 1888, con 55 años. Por esta razón, Tubino quiso conocer en profundidad la residencia palatina sevillana, de manera que pudiera contextualizar con todo lujo de detalles de qué manera aconteció la vida del monarca en dicha ciudad.

Antes de explorar entre sus muros, hizo acopio de las múltiples referencias literarias que hacían mención, por muy leve que fuera, a la realidad constructiva del Real Alcázar: desde la crónica del moro Raxis hasta su coetáneo Pedro de Madrazo. Una vez analizadas y confrontadas las noticias proporcionadas por dichas fuentes literarias, cayó en la cuenta de una circunstancia de importancia capital para su estudio: se desconocía por completo la existencia de construcciones palatinas anteriores al reinado de Pedro I, o, al menos, no se había demostrado con sólidos argumentos que estas pudieran aún subsistir.

No contento con el resultado de la rebusca bibliográfica, su compromiso con la verdad histórica provocó que no se conformara con registrar los testimonios historiográficos de sus predecesores. Su formación, marcadamente positivista, y por tanto, fundamentada en la búsqueda de la analogía entre los métodos de las ciencias naturales y los de los estudios histórico-artísticos, le impulsaron a tomar para su investigación únicamente lo que él mismo podía estudiar, cotejar y asegurar. Sólo así puede comprenderse que uno de sus primeros objetivos en este trabajo consistiera en refutar las opiniones escritas por anteriores estudiosos de la realidad material del Alcázar, que desde su punto de vista, se basaban en débiles indicios.

Y llevaba razón pues, hasta entonces, cuanto se había escrito acerca del Alcázar, apenas habían sido

\footnotetext{
${ }^{2}$ Estas investigaciones fueron cuidadosamente explicadas por Francisco M. ${ }^{\mathrm{a}}$ Tubino en un informe inédito enviado a la Real Academia de la Historia, fechado el 15 de marzo de 1885 en el que relató el resultado de sus investigaciones en el Alcázar: Archivo de la Real Academia de la Historia, Comisión de Antigüedades, Expediente sobre el informe de los alcázares de Sevilla, sign.: CASE/9/7970/39; hubo de enviar otro informe a la Real Academia de Bellas Artes de San Fernando que no ha podido ser localizado. También se narran y analizan en Tubino 1886. La transcripción de las citas de dichos documentos se ha llevado a cabo respetando la ortografía original de los textos.
}

elucubraciones por parte de los antiguos cronistas de la ciudad, salvo honrosas excepciones protagonizadas por los primeros "críticos de arte" del siglo XIX (Amador de los Ríos 1874a y 1874b). No debemos olvidar el testimonio de Rodrigo Caro, quien apuntó sobre el Alcázar en el siglo XVII que "el Palacio de los Reyes Moros fue en este mismo sitio, porque alguna parte de su edificio lo muestra así" (Caro 1634: fol. 56). Se refería al Patio de Crucero y a su jardín subterráneo y probablemente, siguiendo sus descripciones, a las que se aludirán más adelante, al Patio del Yeso. Esta noticia fue determinante para Tubino, quien confiaba en que la residencia real de época musulmana aún se conservara camuflada entre los muros del Palacio de Pedro I.

Dominado por una febril actividad investigadora, movió los resortes adecuados para poder explorar el conjunto arquitectónico del Alcázar. Gozando de buena posición social en la ciudad, en la cual se había instalado definitivamente en 1884 (Revuelta 1989: 68), respetado y admirado por sus contemporáneos, no debió resultarle difícil contar con los permisos que le permitiesen adentrarse libremente en su interior. Con el beneplácito de las autoridades competentes, Francisco M. ${ }^{a}$ Tubino procedió a explorar las construcciones del Alcázar y sus alrededores durante los primeros meses del año 1885.

Previo estudio topográfico, -del cual no se han conservado planos, dibujos o cuadernos de campo-, basado en "el reconocimiento geológico que hace algunos años practicamos, en union de muy experimentado naturalista" (Tubino 1886: 209), pudo inducir que parte del terreno ocupado por el conjunto monumental del Alcázar perteneció a la zona que en época protohistórica ocupó el "akrópolis hispalense" (Tubino 1886: 205-220). Este estudio topográfico se vio reforzado por la consulta de testimonios literarios, y por el conocimiento que tenía acerca de los hallazgos materiales casuales registrados a lo largo del tiempo en esta área urbana ${ }^{3}$.

Esta hipótesis sobre el "akrópolis hispalense" condujo a Tubino a formular su tesis de partida: que el Alcázar primigenio de época musulmana, dado su

\footnotetext{
3 Aunque esta teoría de Tubino respecto al "akrópolis hispalense" ha sido perfeccionada gracias a las investigaciones geoarqueológicas llevadas a cabo en el Alcázar, y a sus correspondientes reconstrucciones paleogeográficas (Borja y Barral 2010), estas han acabado por dar la razón a Tubino. Su planteamiento topográfico, aunque no exento de errores en el marco cronológico, fue bastante aproximado a los datos que conocemos en la actualidad. Efectivamente, el área del Alcázar se situaría dentro de los límites del llamado promontorio fundacional de la ciudad (Tabales 1997-1999: t. I, 47), donde se han identificado restos de ocupación protohistórica, el menos, desde el siglo VIII a. C. (Borja y Barral 2010: 34).
} 
privilegiado emplazamiento, siempre estuvo dentro de los límites del "akrópolis", o como él mismo formuló: "que aquí [en el actual emplazamiento del Alcázar], puede colocarse, sin violencia, la habitación normal de Abdalasiz, y de todos sus sucesores" (Tubino 1886: 280). Rehuía por tanto de la teoría argüida por Pedro de Madrazo, quien sostenía que el emplazamiento del Real Alcázar en su actual localización databa de época abbadí (Madrazo 1884: 461) . Por tanto, estas primeras investigaciones le llevaron a considerar que el Palacio de Pedro I no fue la primera construcción regia erigida en aquella localización. Tan sólo le restaba encontrar restos del Alcázar, anteriores al reinado de Pedro I.

Guiado por las fuentes literarias, comenzó la búsqueda de los desaparecidos Patio del Yeso y Palacio del Caracol, sobre cuya existencia se pensaba que nada había sobrevivido a los avatares del tiempo. Se citaban en las crónicas de Pedro I y de Alfonso XI pero nada se sabía acerca de su cronología. A pesar de ello, Tubino perseveró en su certera opinión de que aún se conservaban restos de estas construcciones. Y para hallarlos, sólo era necesario comenzar una búsqueda metódica por el conjunto edilicio.

Para alcanzar este objetivo, no pensó en recurrir a excavaciones arqueológicas, cuya técnica, aún muy rudimentaria, debía conocer; recordemos su amplia experiencia en los estudios sobre Prehistoria. Prefirió poner en práctica un método de investigación basado en la observación directa de las construcciones del Alcázar. Este consistía en el estudio de la morfología de los muros, las distintas tipologías presentes en los paramentos y las relaciones espaciales entre los distintos ámbitos. Esta concepción del estudio de la arquitectura, comparte, a grandes rasgos, la misma base epistemológica de la AA: "partiendo de la lectura muraria de un edificio histórico, se propone el estudio de sus procesos constructivos identificando individualmente los cambios de fábrica en cada uno de los paramentos que la componen" (Carrero 2008: 6). Tubino no llegó a aplicar el análisis estratigráfico en los paramentos, técnica que no se sistematizó exhaustivamente hasta finales de los años ochenta del siglo XX. Pero anteriormente a esta fecha, y como se evidencia en los estudios de Tubino, la lectura de muros ya había sido empleada con anterioridad como

\footnotetext{
${ }^{4} \mathrm{Al}$ respecto es necesario señalar que la hipótesis de Tubino acerca del origen constructivo del Alcázar, ha sido refutada por los estudios de paramentos y sondeos estratigráficos llevados a cabo por Miguel Ángel Tabales, revelando estos que su construcción se llevó a cabo a lo largo del siglo XI y principios del siglo XII (Tabales 2010: 105).
}

instrumento de estudio de los procesos constructivos en la historia de la arquitectura (Carrero 2008: 18). De esta forma, no sólo continuó con la tradición de estudios estilístico-comparativos de sus contemporáneos, sino que fue más allá al comprender que para conocer la realidad diacrónica de la historia constructiva del Alcázar, era necesario estudiar los elementos constructivos que lo conforman desde su caracterización tipológica.

De este análisis esperaba poder encontrar indicios que le guiaran hacia el descubrimiento de los restos palaciegos anteriores al reinado de Pedro I, como así ocurrió. Durante este proceso llamaron su atención varios elementos constructivos que no casaban dentro del entorno circundante. En primer lugar, "en la banda oriental de dicho pátio [de Banderas] algunos arcos antiguos". Estos arcos, en principio podrían ser relacionados con los del callejón de la Judería, pero no coinciden con la localización que les da Tubino en su plano (Fig. 1). También pudiera ser que se refiriera a la primitiva puerta del Alcázar, localizada y estudiada por Miguel Ángel Tabales (2002b), pero tampoco coincide su ubicación en el plano con la real. De modo que, teniendo en cuenta las sucesivas reformas que a lo largo del siglo XX han modificado la fisonomía del lienzo oriental de murallas del Alcázar (Tabales 2002a: 104-105), la identificación de estos arcos se hace muy difícil.

Continúa enumerando: "(...) otro [arco] muy bien trazado (...) al final del Callejón del Agua" que en este caso no puede más que tratarse del arco de la Puerta del Agua, al pie de la Torre del Agua del Alcázar, de cronología almohade (Tabales 2002a: 202). Cita además como elementos sugerentes "el subterráneo dicho Baños de la Padilla, el muro ciclópeo que separa los pátios de la Montería y de Banderas", es decir, el lienzo paramental occidental de la primitiva alcazaba, el "recinto I" del Alcázar (Tabales, 2006); "y sobre todo, el Salon llamado de Justicia" (Tubino 1886: 239). Estos indicios materiales le dieron pie a formular la teoría de que las construcciones que estaba buscando, el Cuarto del Yeso y el del Caracol, "debían estar más o menos alteradas, si ya era que no habían sido destruidas por completo, en la región media del área palatina, hácia el Patio de Banderas y el Apeadero" (Tubino 1886: 238).

Centrando sus exploraciones en esta área, ingresó en un espacio del Alcázar destinado a almacén de maderas y tejas, del cual señala que estaba situado junto a la casa $\mathrm{n}^{\mathrm{o}} 6 \mathrm{acc}^{\mathrm{o}}$ de dicho patio. Gracias a un plano de Joaquín Fernández de 1872, perteneciente al Archivo 


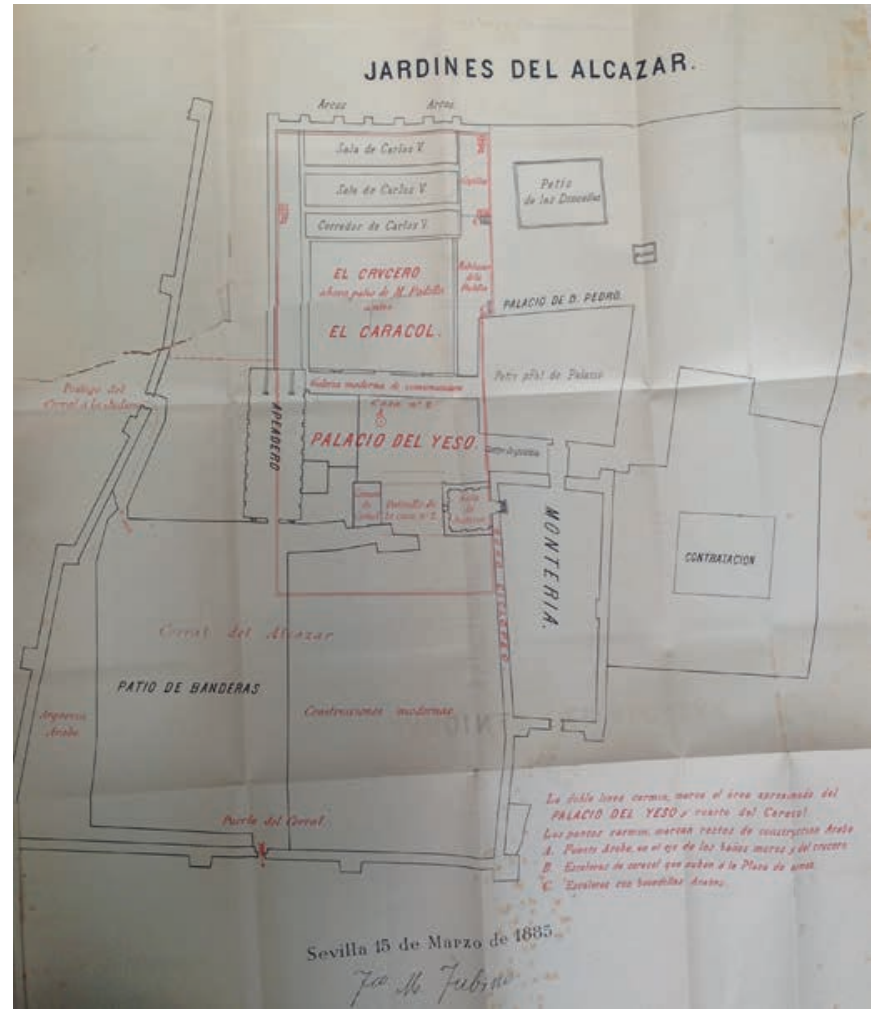

Fig. 1: Francisco M.a Tubino, [Plano del Alcázar], en Estudios sobre el arte en España. Sevilla, 1886. Plano que Francisco M.a Tubino remitió junto al informe de la Real Academia de la Historia, señalando sus descubrimientos en el área correspondiente al Palacio del Yeso y al Cuarto del Caracol y elementos constructivos de origen islámico.

General de Palacio, comprobamos que dicha casa está actualmente rotulada con una $\mathrm{A}$, frente a la ${ }^{\circ} 6$ del Patio de Banderas (Fig. 2). En una segunda habitación de este recinto, próximo al cercano almacén, pudo contemplar "entre los hierros de una ventana alta, un muro antiguo, grandemente mutilado, y en él pedazos de extraña ornamentación mahometana" (Tubino 1886: 239-240). Probablemente se asomara por una de las ventanas altas de lienzo oriental del Patio del Yeso, que comunica con el local accesorio desde donde menciona haber entrado.

Fue en ese momento cuando Tubino redescubrió, aún sin ser consciente de ello, los maltrechos restos del Patio del Yeso. De este recinto se había perdido toda referencia espacial, pues aún no había sido descubierto ni estudiado el fragmentado plano del Alcázar, ejecutado, muy posiblemente, por Vermondo Resta hacia 1608 (García Martín 1979 y Marín 1990 respectivamente), en el que se localizan el "patio del quarto de los yessos" y el "quarto de los yessos" (Fig. 3). Exceptuando este

\footnotetext{
Archivo General de Simancas. Mapas, planos y dibujos, 38, 134
}

plano, no se conserva otro que haya documentado este ámbito hasta que lo redescubriera Tubino.

Sin restar valor a este hallazgo, el historiador José Gestoso advirtió poco después, en 1889, que él ya había visto el muro de "arabescos" perteneciente al frente meridional del Patio del Yeso en 1875, en una de sus numerosas visitas al estudio del pintor Manuel Ussel de Guimbarda. Los restos del patio habían formado parte de su taller, al menos, durante el año 1875 . No obstante, este historiador le atribuyó el mérito a Tubino por haber sabido identificar estos restos correctamente (Gestoso 1889b: 305).

Este muro que apenas pudo vislumbrar, era uno de los frentes de un patinillo interior de la casa $\mathrm{n}^{0} 2$ del Apeadero, tal y como se aprecia en el plano de 1872. A esta se accedía a través del corredor que comunica el Apeadero con el Patio de la Montería (Fig. 2). Esta vivienda era habitaba por aquel entonces por el marqués de Villasegura, Imeldo Serís, que en esas fechas ocupaba el cargo de jefe de la casa de Dña. Isabel II. Es posible que esta casa hubiera mantenido hasta 1885 , año de las investigaciones, la misma estructura que aparece en el plano de 1872, tal y como interpretamos en el escueto plano que trazó Tubino, localizando sus descubrimientos en el Alcázar (Fig. 1).

En el plano de 1872, después de compararlo con el plano de Vermondo Resta (Fig. 3), y con el de Van der Borcht (Fig. 4), puede apreciarse cómo el Patio del Yeso fue profundamente modificado a lo largo de la Edad Moderna, habiéndose tabicado y compartimentado su espacio y mutilado la mayor parte de su estructura y decoración. La lectura estratigráfica de su lado meridional, el que contempló Tubino, revela las múltiples modificaciones a las que fue sometido este ámbito (Tabales 2002a: 40-56). En cambio, los espacios pertenecientes al "quarto del yesso", en el ala septentrional, conservaron en esencia su disposición espacial primigenia (Almagro 2015: 18).

Tubino confrontó sus descubrimientos con testimonios de antiguos cronistas de la ciudad, especialmente con el de Rodrigo Caro. Este estudioso del siglo XVII ya había advertido la antigüedad de la estancia que llama "cuarto del Maestre", que localiza "luego como se entra [desde el Apeadero], á la mano derecha" (Caro 1634, fol. 56). También había llamado la atención sobre

\footnotetext{
${ }^{6}$ Las modificaciones llevadas a cabo en el Patio y Cuarto del Yeso durante la Edad Moderna fueron documentadas por José Gestoso (Gestoso 1889b: 327-334) y analizadas por Ana Marín (Marín 1990). Igualmente, las transformaciones de esta área pueden apreciarse con claridad en los planos de Van der Borcht (1759) y el de Joaquín Fernández (1872).
} 


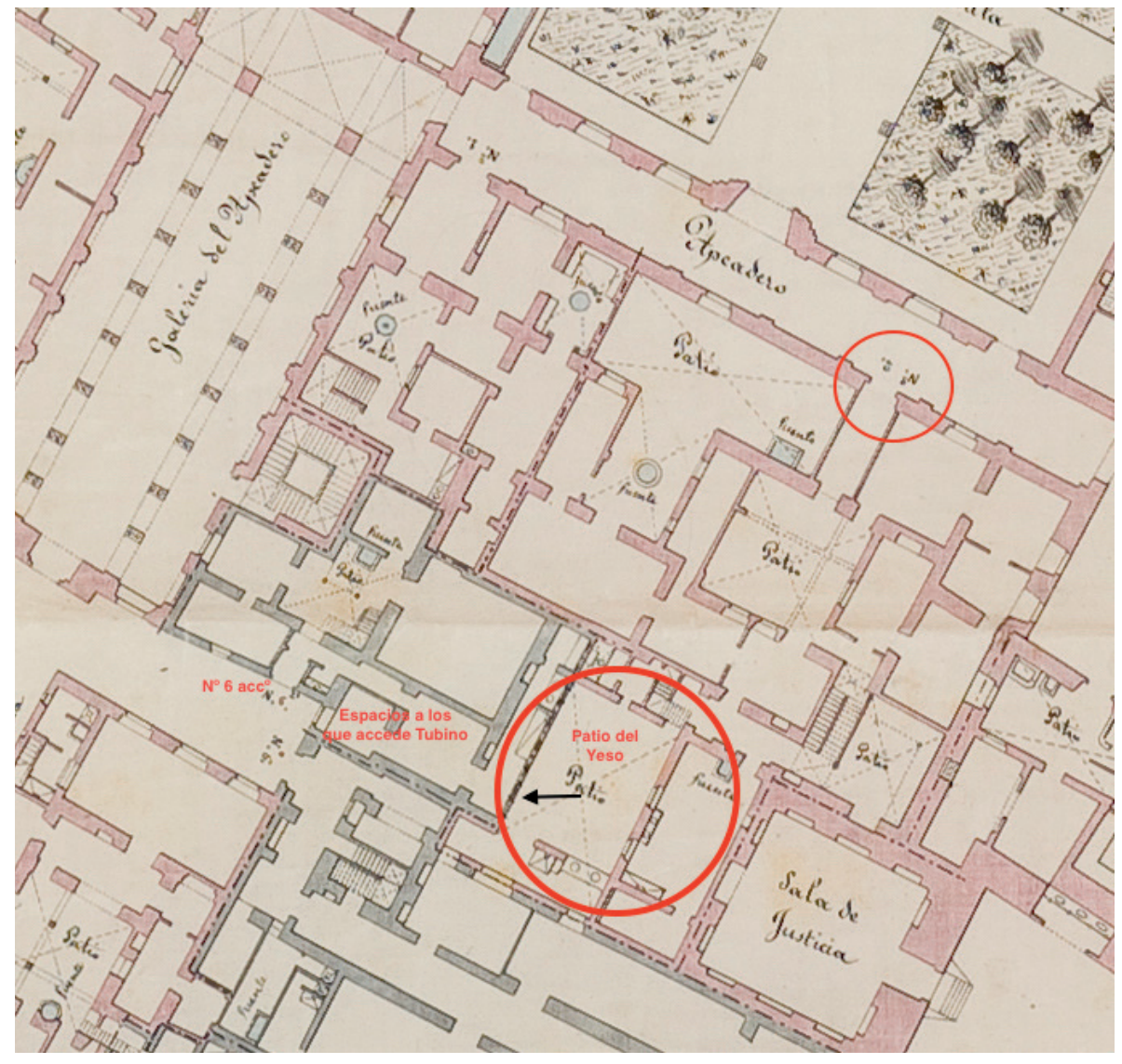

Fig. 2: Joaquín Fernández, Plano general de los Reales Alcázares de Sevilla y sus pertenencias declarado del Patrimonio de la Corona. Sevilla, 25 de enero de 1872. Archivo General de Palacio nº 1239. Detalle del plano en el que se aprecia en la zona superior derecha la entrada a la casa no 2 del Apeadero; dentro de sus límites, marcados con línea discontinua, aparece incluido el Patio del Yeso, junto a la Sala de la Justicia, apreciándose su espacio muy compartimentado. La flecha negra señala la ubicación de la ventana por donde Tubino vio el frente meridional del Patio del Yeso.
Fig. 3: Vermondo Resta (atribuido a), Plano de los Alcázares de Sevilla para lo que toma el audiencia, (s.f.) (hacia 1608), Archivo General de Simancas, Mapas, planos y dibujos, 38-134. Este plano es el testimonio documental más antiguo que nos ilustra acerca de la planta y disposición del Patio y Cuarto del Yeso. Su comparación con la figura n० 1 y las $n^{\circ} 3$, permite comprobar cómo ha sido este un espacio muy transformado a lo largo de los siglos, hasta su redescubrimiento en 1885 por Tubino.

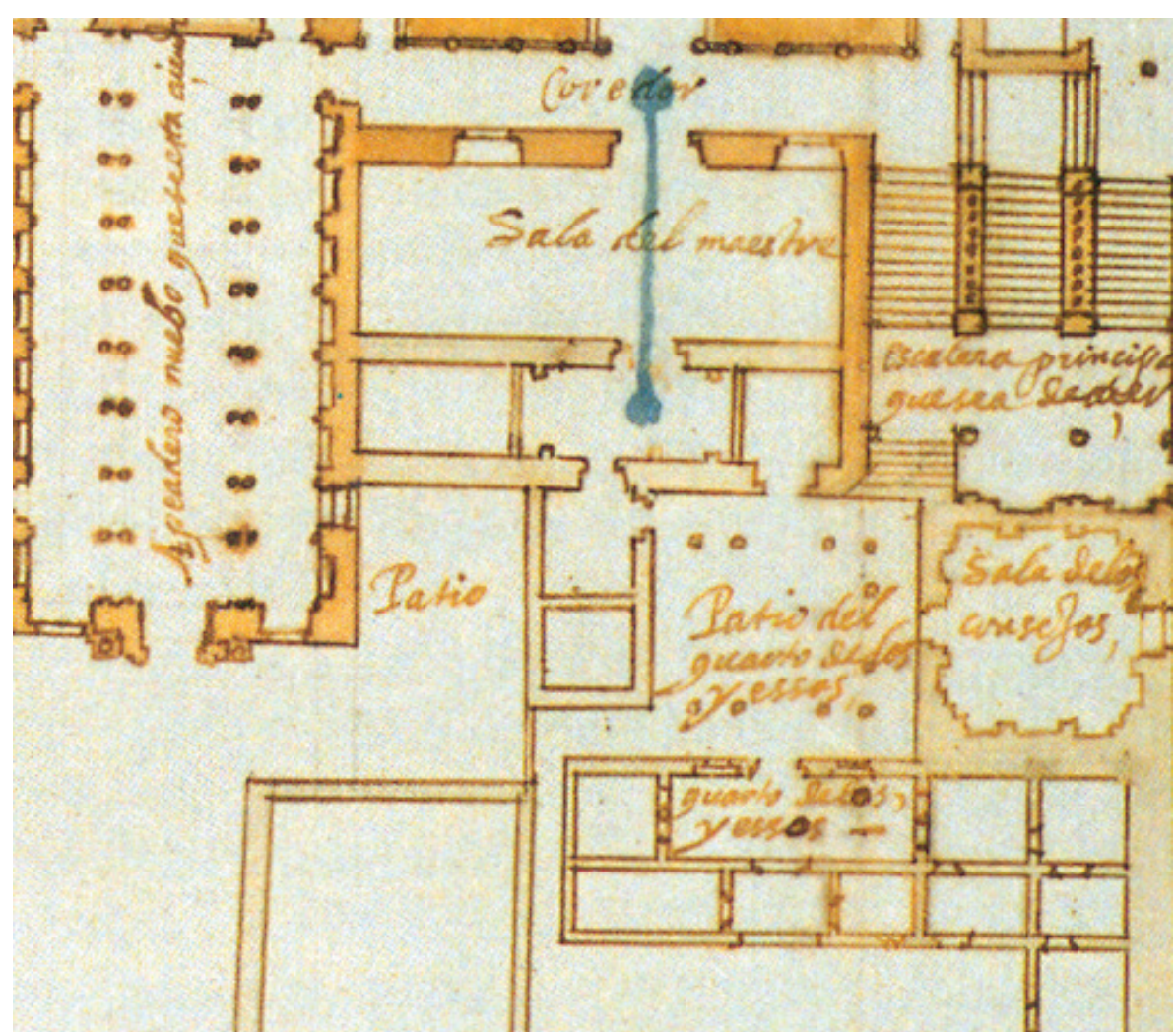




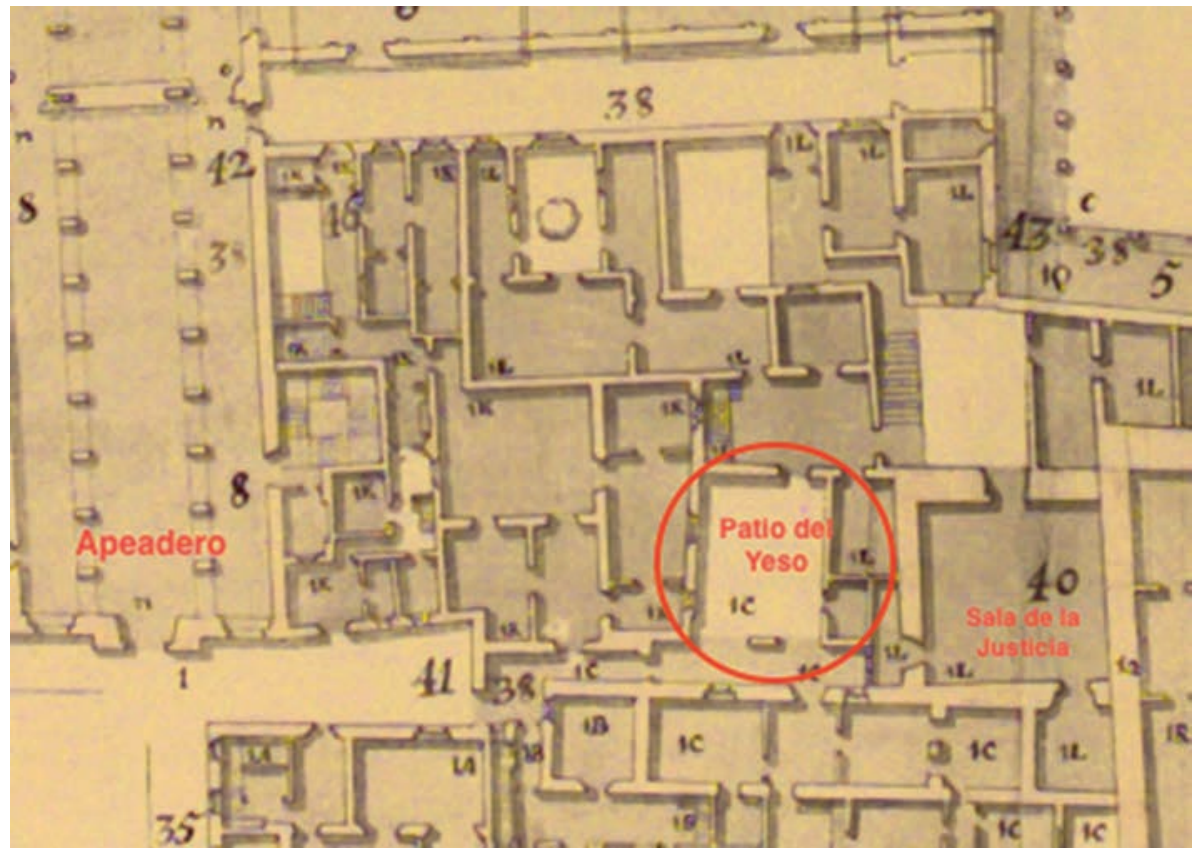

Fig. 4: Sebastián van der Borcht, Plano de los Reales Alcázares de Sevilla con sus jardines y sus posadas accesorias (hacia 1759), Archivo General de Palacio, plano no 4581. En este fragmento del conocido plano de Sebastián van der Borcht, observamos cuán profundamente se ha modificado el Patio y Cuarto del Yeso, apareciendo su espacio compartimentado y dividido entre dos ámbitos diferentes del Alcázar: la $1 \mathrm{~K}$ que se corresponde con la posada del Escribano, y la $1 \mathrm{C}$ que se trata de la posada del Médico. el origen musulmán de "algunos caracteres arábigos que se descubren en los yesos" (Caro 1634: fol. 56). Con el apoyo de estas antiguas observaciones, Tubino supo identificar aquel maltrecho muro con el olvidado Patio del Yeso. De su fachada meridional, realizó un fidedigno dibujo, especialmente minucioso al mostrar bien diferenciando lo conservado de lo cubierto o mutilado (Fig. 5).

Aunque es bien conocida la importancia que tuvo en su época el descubrimiento del Patio del Yeso por Francisco M. ${ }^{\text {a }}$ Tubino en 1885, debemos valorarlo como un punto de inflexión en la historiografía sobre el Alcázar. Supuso el conocimiento fehaciente de la existencia de restos de construcciones musulmanas en el mismo, existencia anteriormente insinuada pero nunca debidamente argumentada.

Pero no contento con este importante hallazgo, Tubino prosiguió sus investigaciones en el Patio del Crucero, entonces 1lamado de Doña María de Padilla. En este recinto practicó un estudio morfotipológico de los paramentos de sus galerías subterráneas, interpretadas entonces como baños ${ }^{7}$. Estas exploraciones, le llevaron a confirmar su hipótesis previa: que el Palacio

El Patio de Crucero fue analizado arqueológicamente por el equipo del profesor Tabales en 1998 (Tabales 2002a: 57-88).

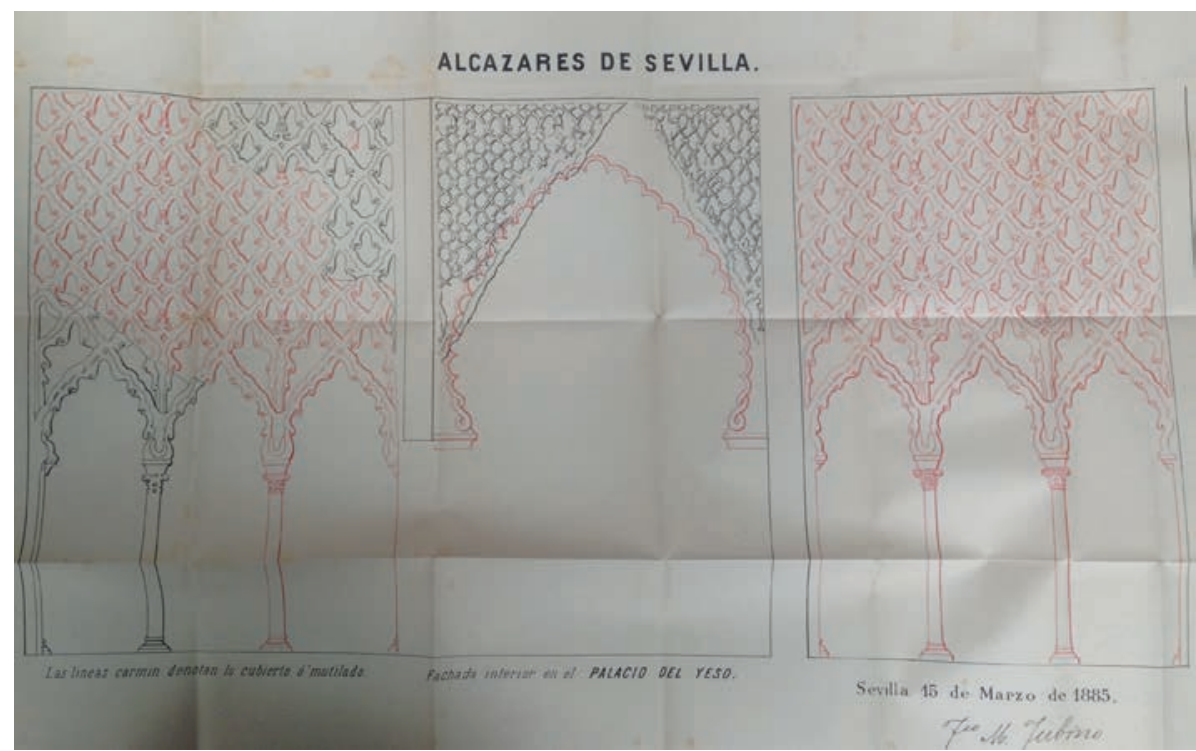

Fig. 5: Francisco M.a Tubino, "Fachada interior en el Palacio del Yeso", en Estudios sobre el arte en España. Sevilla, 1886. Minucioso dibujo del alzado del frente meridional del Patio del Yeso. El interés de Tubino por el análisis formal de los arcos que conforman el maltrecho pórtico, queda bien demostrado en su afán por distinguir las zonas que aún se conservaban y presentar una hipótesis de reconstrucción de las formas para las zonas mutiladas. 
de Pedro I estuvo precedido en el tiempo por otras construcciones en el Alcázar, y que precisamente uno de los ámbitos más antiguos era el Patio de Crucero. Esta conclusión estaba reforzada, una vez más, por el testimonio de Rodrigo Caro. Caro ya había descrito a la perfección el citado patio antes de su remodelación dieciochesca; opinaba además que ese espacio era, junto al Cuarto del Maestre "del Antiguo Alcázar de los Moros" (Caro 1634: fol. 56)

Lejos de perpetuar la tradición romántica que avivaba la leyenda de los amores de Pedro I con María de Padilla, y sus encuentros en el evocador ambiente que les proporcionaba el escenario de los míticos "baños", Tubino rescató del olvido la correcta identificación de estos subterráneos con los restos del jardín inferior del Patio de Crucero musulmán ${ }^{8}$, ya adelantada por Rodrigo Caro. Reconoció además que esta antigua construcción islámica había mantenido su estructura esencial, aún con severas transformaciones durante la Edad Media, hasta las remodelaciones llevadas a cabo por Van der Borcht después del terremoto de Lisboa (Tubino 1886: 247-248 y 254$)^{9}$.

Anteriormente hemos señalado que otro de los intereses de Tubino fue la localización del Cuarto del Caracol, también denominado Palacio Gótico. Siguiendo con la exploración de los subterráneos del Alcázar adyacentes a los llamados Baños de Doña M. ${ }^{\mathrm{a}}$ de Padilla, justo bajo el Palacio Gótico, descubrió "altas bóvedas, con aristones robustos y arcos apuntados, que se apean en columnas de jaspe, con la mitad del fuste enterrado, y capiteles propios de la transición entre el estilo románico y ojival". Estos indicios le llevaron a concluir, acertadamente, que sobre estas estructuras se encontraba el Cuarto del Caracol. Para corroborar esta idea y justificar la denominación de aquel espacio, buscó concienzudamente y descubrió en él cuatro escaleras de caracol que comunicaban con la planta alta (Tubino 1886: 259-260). Esta acertada interpretación supuso el redescubrimiento del Cuarto del Caracol, estancia ya conocida pero cuyo origen islámico y reconstrucción posterior en época cristiana se desconocía por completo. A esta identificación, Tubino añadió que "esta parte del Alcázar fue modificada, en lo preciso, después de la

\footnotetext{
${ }^{8}$ A pesar de la importancia de la identificación del origen islámico de este espacio, su coetáneo y amigo José Gestoso, no se hizo eco del descubrimiento (cfr. Gestoso 1889b: 376-379).

${ }^{9}$ Las investigaciones actuales han corroborado esta teoría (Almagro 2002: 189). Así pues, fue Francisco M. ${ }^{a}$ Tubino, y no Leopoldo Torres Balbás, como se ha señalado (Almagro 1999: 331), el primer investigador del Alcázar que adscribió un origen islámico al Patio del Crucero.
}

reconquista, para apropiar la construcción arábiga, á las necesidades de la vida cristiana" (Tubino 1886: 259). Es decir, que defendió el origen islámico de la construcción del Cuarto del Caracol, considerando la fábrica gótica una reconstrucción del Alcázar islámico ${ }^{10}$.

De estas investigaciones arqueológicas que llevó a cabo Francisco M. ${ }^{\mathrm{a}}$ Tubino en el Alcázar de Sevilla, consideramos las más relevantes el redescubrimiento del Patio del Yeso y la identificación del Cuarto del Caracol. No debemos pasar por alto la adscripción del Patio de Crucero al periodo islámico del conjunto palaciego. Y además planteó otras interesantes hipótesis acerca de los avatares constructivos del conjunto monumental. Estas teorías que también recogió en su libro Estudios sobre el Arte en España (Tubino 1886), si bien son de índole secundaria y han sido refutadas por investigaciones recientes, constituyen buena muestra de la exhaustividad del trabajo que puso en práctica. Presentamos una de ellas, referente al posible origen islámico del Palacio de Pedro I.

Tubino estimaba que este conjunto "no se sacó de cimientos, ni se derribó, el que ántes existía, limitándose los alarifes, á modificar, adaptar y embellecer lo anterior" (Tubino 1886: 280). En otras palabras, consideró que el rey no dispuso edificar un palacio ex novo, sino que se limitó a ordenar la restauración de construcciones anteriores de origen islámico. Las razones aducidas para sostener esta opinión, se fundamentaban, principalmente, en la presencia de elementos constructivos de cronología anterior a la conquista cristiana, por ejemplo en el salón de Embajadores: "se señalan capiteles, anteriores al siglo XIV. ¿Se adaptaron cuando la restauración, ó estaban donde los vemos desde época precedente?" (Tubino 1886: 273) ${ }^{11}$.

\footnotetext{
${ }^{10}$ Esta hipótesis fue corroborada por el profesor Rafael Manzano apoyándose en su aspecto externo, que presenta similitudes con obras como el Alcázar de Córdoba o la Mezquita aljama de Sevilla (Manzano 1995: 99). Pero las investigaciones más recientes no dan la razón a Tubino, puesto que para edificar el Palacio Gótico, previamente se derribó gran parte del edificio almohade anterior (Tabales 2010: 271-282). Este desacierto no ha de ser óbice para valorar el mérito de Tubino al identificar acertadamente el Cuarto del Caracol, pues su estructura, planta y disposición fueron muy modificados durante las obras posteriores al terremoto de 1755 (Almagro 2007: 156).

${ }^{11}$ Esta hipótesis ha sido rechazada actualmente, y se ha demostrado que la construcción del palacio de Pedro I fue una operación radical, en la que no se reutilizó ninguna estructura previa (Tabales 2010: 290-293), pero su propuesta demuestra el interés de Tubino por plantear las secuencias constructivas del Alcázar. Al respecto, cabe recordar que la presencia de elementos constructivos de fecha anterior a la construcción del palacio de Pedro I, sigue siendo para algunos investigadores un indicio que sugiere la posibilidad de que se reaprovecharan estructuras almohades previas al actual recinto cristiano (Cómez 2007: 333-334 y Cómez 2013: 124-135), tal y como sostenía Tubino.
} 


\section{CONSIDERACIONES ACERCA DEL MÉTODO DE INVESTIGACIÓN DE FRANCISCO M. a TUBINO}

Al dedicar al Alcázar de Sevilla un capítulo de su obra Estudios sobre el arte en España (Tubino 1886), Tubino pretendía dar a conocer sus descubrimientos en este conjunto monumental. Su objetivo era demostrar la existencia en el mismo de construcciones anteriores al reinado de Pedro I. Para tal fin presentó, con un discurso bien hilvanado, su teoría acerca del origen primigenio del Alcázar. El redescubrimiento del Patio del Yeso y del Cuarto del Caracol, y el reconocimiento de los orígenes del Patio de Crucero, fueron determinantes para la comprensión de la realidad material del edificio. Pero también fueron reveladoras las técnicas de investigación empleadas por Tubino para el estudio de estos restos palatinos, distintas a las empleadas hasta ese momento por los eruditos decimonónicos españoles.

Gracias a la lectura de los citados Estudios... y del informe conservado en la Real Academia de la Historia, hemos podido conocer y analizar el método de trabajo que llevó a cabo durante sus investigaciones en el Alcázar de Sevilla, que comparte planteamientos epistemológicos y procedimentales con la AA. Pero además, puso en práctica otros que en la actualidad se consideran propios de la HA. En definitiva, encontramos en la labor de Tubino, un destacado ejemplo de conciliación entre la AA y la HA, sin obviar las diferencias existentes entre el estudioso decimonónico, y el actual oficio de historiador del arte y el de arqueólogo.

A pesar de ello, y con las pertinentes limitaciones de su oficio, nos apoyamos en la opinión del profesor Manzano, quien afirma sobre Tubino y sus investigaciones en el Alcázar de Sevilla, que fue "el primer estudioso que exploró aquel prodigioso conjunto de edificios con verdadero afán científico y espíritu de arqueólogo" (Manzano 1999: IX). Suscribimos su juicio pues consideramos que, efectivamente, fueron las suyas las primeras investigaciones metódicas y sistemáticas que se realizaron en este lugar. De esta forma, Tubino logró superar los estudios artísticos de la tradición romántica anterior. Una tradición que adolecían de falta de rigor, fundamentalmente debido a la repetición de leyendas y tópicos no contrastados y a la inclusión de opiniones personales carentes de argumentos. Aquella aún deficiente historiografía decimonónica, se caracterizaba por la tendencia hacia la fabulación, a la par que se mostraba propicia a la recreación en los aspectos estéticos.
Ese «verdadero afán científico» de Tubino que menciona Manzano, estuvo respaldado por su adscripción a dos corrientes: el positivismo, entendido como método, no como escuela filosófica, ante la cual Tubino sostuvo una postura crítica, dada su firme defensa del evolucionismo (Ayarzagüena 1994: 44); y el formalismo.

Las corrientes positivistas, fundamentadas en la confianza en el método científico, comenzaron a llegar a nuestro país procedentes de Europa a lo largo del siglo XIX. Tubino se convirtió en un adelantado a su tiempo, pues las conoció en sus países de origen, trayéndolas a España. Así lo demuestra su falta de reconocimiento hacia los estudios histórico-artísticos sobre el Alcázar de otros investigadores, por no haber sido elaborados con base en una metodología experimental. La profesora María Belén recoge la opinión que Tubino tuvo respecto al método que debe guiar a ciencias como la Arqueología: "[los estudios de los grupos humanos del pasado] han entrado en el círculo de las ciencias positivas $y$, por tanto, se les aplica en rigor el método que en éstas predominan" (Belén 2002: 9). Así, la postura epistemológica de Tubino supuso una ruptura radical con la tradición historiográfica romántica, deudora del idealismo hegeliano, para abrirse a los nuevos procedimientos experimentales que concedían mayor importancia a las ciencias de la naturaleza.

El método al cual se acogió Tubino, fue explicado claramente por su coetáneo Sales y Ferré en 1881, quien, como él, contrario al Positivismo filosófico, aclaraba lo siguiente acerca del término: «...[investigación] positiva en el sentido del método, que sin desconocer a la inteligencia la cualidad de fuente propia de conocer, exige sin embargo a todo conocimiento, para que sea científico, base experimental; que considera a la experiencia no sólo como fuente de conocer, sino como medio de comprobación universal, de tal manera que ningún conocimiento, por elevado que sea, debe ser considerado como tal si no tiene alguna raíz en el suelo de la experiencia» (Sales y Ferré 1881: 6) ${ }^{12}$. Este aserto haya su paralelo en un escrito anterior de Tubino, fechado en 1876, señalando sobre su formación: "Emprendí el estudio sistemático y teórico de la Arqueología prehistórica, acompañándolo de trabajos prácticos" (cit. por Belén 2002: 8), claro exponente de la necesidad de la experiencia en el aprendizaje de la nueva disciplina.

\footnotetext{
12 Sales y Ferré, M. 1881: El hombre primitivo y las tradiciones orientales: la ciencia y la religión. Conferencias dadas en el Ateneo Hispalense. Sevilla, cit. por Aguilar 1990: 95-96.
} 
Por otro lado, Tubino hizo uso del método formalista, de tanto arraigo entre los futuros historiadores del arte a partir de comienzos del siglo $\mathrm{XX}^{13}$, en tanto clasificaba en épocas las estructuras arquitectónicas, siempre en función de sus caracteres o apariencia formal. Esta actitud debe entenderse como contrapuesta al idealismo romántico propio de la historiografía de la primera mitad del XIX, más apegada al historicismo y a los métodos literarios. Los estudios formalistas vinculan la estética sólo con la forma, razón por la que resulta imprescindible la exhaustiva clasificación estilística, casi taxonómica, de lo existente. En efecto, así hubo de actuar Tubino, estudiando con minuciosidad los restos arquitectónicos que había redescubierto en el Alcázar, especialmente el Patio del Yeso, que supo identificar como almohade. A esta conclusión llegó tras poner en práctica completos estudios comparativos con la arquitectura del norte de África. Argumentando su adscripción del Patio del Yeso al arte almohade, señalaba: "al expresarnos así, no consultamos texto alguno, concretándonos á la observación de los caracteres artísticos que las fábricas ofrecen. A ellos nos atenemos, como Cuvier se atenía á los restos fósiles de los mamíferos antidiluvianos, para reconstruir la totalidad de la osamenta" (Tubino 1886: 257) ${ }^{14}$.

Al margen de estas corrientes europeas en las que Tubino apoyó sus investigaciones, queremos destacar la similitud entre el método de trabajo que empleó en los estudios arqueológicos y artísticos del Alcázar de Sevilla, con los planteamientos epistemológicos y las técnicas de la AA. Estos no surgieron de la nada, de hecho, podemos rastrear sus precedentes desde el comienzo mismo de la Arqueología en el siglo XVI (Quirós 2002: 28). Y en la obra de Tubino apreciamos una cercanía a los postulados que sustentan la AA, más incluso que a la actual HA.

El punto de contacto más evidente entre Tubino y la AA, se encuentra en el enfoque de sus estudios sobre el Alcázar y su arquitectura. "Fíjanse los críticos [de arte] en el exterior, en lo aparente, hablan (...) de paredes embellecidas con azulejos, mocárabes y frisos (...), pero ni una sóla linea, sobre el aparejo, la construcción y la extructura, que después de todo, son en su conjunto, lo sustantivo del arte arquitectónico" (Tubino 1886:

\footnotetext{
${ }^{13}$ Alois Riegl fue el historiador del arte que desarrolló con mayor libertad los planteamientos formalistas (Portús 2015: 435).

${ }^{14}$ El arquitecto e historiador de la arquitectura Gotfied Semper, ya había ideado su propio método de estudio de evolución de las formas artísticas, hacia 1860, inspirado en las teorías paleontológicas del naturalista francés Georges Cuvier (Kultermann 1996: 148-150).
}

XXIII). Esta perspectiva de estudio coincide con los actuales planteamientos epistemológicos que presenta la AA. La propuesta de Tubino rompe con la historiografía artística coetánea, que se reducía a ser una historia de las Bellas Artes convertida en un género literario más, preocupada en generar textos formalmente bellos y no tanto en la adscripción de sus trabajos a un método científico (Carrero 2008: 20-21). Tubino en cambio estuvo mucho más preocupado por hacer una lectura arqueológica del edificio, y así llegar a comprender mejor su evolución histórica, "la compleja textura y densidad biográfica de la memoria petrificada" (Azkárate 2008: 59), que a día de hoy se preocupa por reivindicar la AA.

De hecho, Tubino advertía con claridad de los peligros que conlleva un excesivo apego por la "historia de los estilos", y a los usos y abusos que se practicaban, y se siguen practicando, adscribiendo determinadas construcciones a un solo periodo histórico (Azkárate 2008: 63). En estas afirmaciones subyace el interés por despojar a la arquitectura de su revestimiento decorativo para conocer la realidad de su proceso constructivo.

Por otro lado, y aunque Tubino no llegó a aplicar el método estratigráfico al estudio de las construcciones del Alcázar, la relación entre su método de investigación y el de la AA es constatable. Este último se basa fundamentalmente en la adaptación de determinadas técnicas de la excavación arqueológica, especialmente aquellas vinculadas a la estratigrafía, que recordemos tiene su origen en fundamentos geológicos. En línea con esto último habría que entender las investigaciones de Tubino. La aplicación de los métodos arqueológicos para el estudio de la arquitectura, supuso todo un hito en su época. Él, que apenas había excavado en España empleando las nuevas técnicas, las aplicó por encima de la "cota 0" de los edificios: "quisimos averiguar (...) merced á los restos de construcciones que se conservan todavía" (Tubino 1886: 236). Con ello buscaba interpretar la realidad constructiva de los mismos y sus avatares temporales con metodología arqueológica.

El estudio morfotipológico de los paramentos del Alcázar no se había llevado a cabo hasta entonces. Sí habían prestado atención sus coetáneos, como José Amador de los Ríos, al estudio formal de los aspectos decorativos de este conjunto monumental (Amador de los Ríos 1874a y 1874b), pero no a su realidad constructiva, ni a la consideración de que esta era producto de una serie de intervenciones sucedidas a lo largo de los siglos. Este es el matiz que diferencia a Tubino de los estudiosos de la arquitectura histórica de su tiempo, 
y que lo convierte en un precursor de los trabajos de la AA, aún sin emplear la lectura estratigráfica.

Por otro lado, Tubino quiso vincular esta nueva forma de estudiar las edificaciones con los estudios artísticos. Con esta acertada combinación, superaba la barrera interpuesta por los estudios filológicos y estilísticos. De esta forma, contribuyó a mejorar el conocimiento de la realidad constructiva del Alcázar de Sevilla, fundiendo a la perfección métodos de investigación arqueológicos y artísticos. En relación a su aplicación, Tubino asegura que "Requiérese no escasa perspicacia, y hallarse familiarizado con este linaje de estudios, para poder discernir lo propio, de lo añadido, y á veces, no hay medio de obtener esta separación" (Tubino 1886: 262).

\section{CONCLUSIÓN}

La perspectiva expuesta ilustra un cambio de paradigma en la historiografía artística decimonónica, que no alcanzaría su máximo desarrollo hasta comienzos del siglo XX con personajes como Manuel GómezMoreno y Leopoldo Torres Balbás. Y aunque en fechas recientes se ha demostrado la inexactitud de muchas de sus hipótesis ${ }^{15}$, Tubino fue en España un precursor de los actuales estudios que lleva a cabo la AA sobre la arquitectura monumental, tanto epistemológica como instrumentalmente.

Sus investigaciones en el Alcázar evidencian, una vez más, la conveniencia de acometer los estudios de la arquitectura histórica a partir de trabajos interdisciplinares. No en vano, se ha señalado que "hay capítulos de la investigación histórica en los que la HA y Arqueología se entrelazan y confunden" (Arce 2009: 22), como hemos podido comprobar. En línea con esta circunstancia, Luis Caballero (2012: 102) se considera heredero de una tradición de historiadores entre los cuales no se aprecian diferencias entre el historiador del arte, el arqueólogo y el arquitecto, como lo fueron Vicente Lampérez, Josep Puig i Cadafalch o el ya citado Leopoldo Torres Balbás.

Teniendo en cuenta estas consideraciones respecto a la estrecha relación entre HA y AA, no queda otra opción posible más que la necesidad de coexistencia de ambas en los estudios de arquitectura histórica. Es por ello que en línea con otros investigadores (Brogiolo 1995: 32; Carrero

\footnotetext{
${ }^{15}$ Vid. p. 11
}

2008: 16; Caballero 2012: 105-106; Moreno 2014: 16) proponemos a los historiadores del arte especializados en el estudio de la arquitectura, su apertura hacia los métodos que se aplican en la AA. Referentes de la HA ya nos han advertido de la necesidad que tiene un historiador de la arquitectura medieval en formarse debidamente en técnicas arqueológicas (Borrás 2001: 176) y más concretamente, añadiríamos nosotros, en AA. La excesiva especialización de los métodos de la HA puede limitar nuestra visión, máxime si prolongamos una investigación y una docencia continuista con la "historia de los estilos". A pesar de haber quedado obsoleta hace años, esta tendencia historiográfica aún se mantiene en las aulas universitarias, sin renovación metodológica alguna procedente de la AA, que permitiría mayor rigor en las investigaciones (Arce 2009: 24.). Y aunque el historiador del arte normalmente se ha mostrado interesado por el conocimiento diacrónico del edificio, debe aprovechar las aportaciones de la AA, comenzando a familiarizarse con las novedades metodológicas que le son propias, aplicándolas a su práctica profesional.

\section{AGRADECIMIENTOS}

Manifestamos nuestra gratitud hacia quienes nos han ayudado durante la elaboración de este trabajo, que ha sido realizado gracias a un contrato de formación predoctoral (Personal Investigador en Formación P.I.F.) del V Plan Propio de la Universidad de Sevilla.

\section{BIBLIOGRAFÍA}

Acosta Sánchez, J. 1998: "Francisco María Tubino y Rada: Federalismo y Proto-Andalucismo en el XIX”, Estudios regionales, 52, pp. 255-276.

Aguilar Criado, E. 1990: Cultura y Folklore popular en Andalucía (Los origenes de la Antropología). Sevilla.

Almagro Gorbea, A. 1999: "El Patio del Crucero de los Reales Alcázares de Sevilla”, Al-qantara: revista de estudios árabes, 20, pp. 331-376.

Almagro Gorbea, A. 2002: "El análisis arqueológico como base de dos propuestas: El Cuarto Real de Santo Domingo (Granada) y el Patio del Crucero (Alcázar de Sevilla)", Arqueología de la Arquitectura, 1, pp. 175-192.

Almagro Gorbea, A. 2007: "Los Reales Alcázares de Sevilla", Artigrama, 22, pp. 155-185.

Almagro Gorbea, A. 2015: "Los jardines andalusíes y mudéjares del Alcázar de Sevilla”, en Los jardines del Real Alcázar de Sevilla. Historia y arquitectura desde el medievo islámico al siglo XX. Sevilla, pp. 1-39.

Amador de los Ríos, J. 1874a: "Puertas del Salón de Embajadores del Alcázar de Sevilla", Museo Español de Antigüedades, III, pp. 433-470.

Amador de los Ríos, J. 1874b: Sevilla pintoresca. Sevilla.

Arce Sainz, F. 2009: "Historia de Arte, Arqueología de la Arquitectura y el telescopio de Galileo", Arqueología de la Arquitectura, 6, pp. 21-29. 
Arias Castañón, E. 1990: "Francisco María Tubino y el diario La Andalucía ante la Primera República: Patria y Federalismo", en Actas IV Congreso sobre el Andalucismo histórico. Sevilla, pp. 263-280.

Ayarzagüena Sanz, M. 1994: "Pioneros. Francisco M. a Tubino y Oliva (18341888)", Revista de Arqueología, 156, pp. 42-45.

Ayarzagüena Sanz, M. 2004: "Francisco María Tubino y Oliva", Zona Arqueológica, 3, pp. 197-201.

Azkarate Garai-Olaun, A. 2002: "Intereses cognoscitivos y praxis social en Arqueología de la Arquitectura", Arqueología de la Arquitectura, 1, pp. 55-71.

Azkarate Garia-Olaun, A. 2008: "La Arqueología de la Arquitectura en el siglo XXI", Arqueología de la Arquitectura, 5, pp. 11-13.

Belén Deamos, M. 1991: "Apuntes para una historia de la arqueología andaluza: Francisco M. Tubino (1833-1888)”, Boletín del Museo Arqueológico Nacional, IX, 1-2, pp. 7-15.

Belén Deamos, M. 2002: "Francisco María Tubino y la arqueología prehistórica en España”, en Arqueología fin de siglo: la arqueología española de la segunda mitad del XIX (I Reunión Andaluza de historiografía arqueológica), Sevilla, pp. 43-55.

Bianchi Bandinelli, R. 1982: Introducción a la arqueología clásica como historia del arte antiguo. Madrid

Borja Barrera, F. y Barral Muñoz, M. A. 2010: "Secuencia geoarqueológica y reconstrucción paleogeográfica", en Tabales Rodríguez, M. A. 2010: El Alcázar de Sevilla. Reflexiones sobre su origen y evolución en la Edad Media. Memoria arqueológica 2000-2005. Sevilla, pp. 25-38.

Borrás Gualís, G. 2001: Cómo y qué investigar en historia del arte: una crítica parcial de la historiografia del arte español. Barcelona.

Boto, G. y Martínez, A. M. 2010: "Historiar la Arquitectura medieval. Intersecciones epistemológicas de la Historia del Arte y la Arqueología de la Arquitectura", Arqueología de la Arquitectura, 7, pp. 263-275.

Brogiolo, G. P. 1995: “Arqueología estratigráfica y restauración”, Informes de la Construcción, 46, 435, pp. 31-36.

Brogiolo, G. P. 2002: “L'Archeologia dell'architettura in Italia nell'ultimo quinquennio (1997-2001)", Arqueología de la Arquitectura, 1, pp.19-26.

Caballero Zoreda, L. 2012: “A propósito del centenario del 711. Apuntes sobre método de la Arqueología de la Arquitectura”, en Momplet, A. E., Moreno, F. J. y Silva, N. (eds.), 711: el arte entre la Hégira y el califato Omeya de al Andalus, Anales de Historia del Arte, 23, Vol. Ext. pp. 101-130.

Caro, R. 1634: Antiguedades y principado de la ilustrissima ciudad de Sevilla y Chorographia de su convento iuridico, o antigua Chancilleria... Sevilla.

Carrero Santamaría, S. 2008: "Teoría y método en la Historia de la Arquitectura Medieval. Algunas reflexiones”, en Seminari d'estudis històrics 2007: Arqueologia de l'arquitectura, pp. 5-27. Palma de Mallorca.

Cómez Ramos, R. 2007: "Historia del arte y arqueología en los nuevos hallazgos del Alcázar de Sevilla”. Archivo hispalense: Revista histórica, literaria y artística, 90, pp. 313-334.

Cómez Ramos, R. 2013: "El Alcázar bajo medieval", Apuntes del Real Alcázar de Sevilla, 14, pp. 120-137.

Díaz-Andreu, M. 1995: “Arte y Arqueología: la larga historia de una separación”, en Historiografia del Arte Español en los siglos XIX y XX (VII Jornadas de Arte), Madrid, pp. 151-160.

Díaz-Andreu, M., Mora, G. y Cortadella, J. (coords.) 2009: Diccionario histórico de la Arqueología en España. Madrid.

García Martín, E. 1979: "Dos planos del Alcázar de Sevilla”, Boletín del Seminario de Estudios de Arte y Arqueología: BSAA, 45, pp. 439-443

Gestoso y Pérez, J. 1889a: Necrología del Excmo. Señor D. Francisco María Tubino... Sevilla. Sevilla.
Gestoso y Pérez, J. 1889b: Sevilla monumental y artística. Sevilla.

González-Deleito, N. 1968: El escritor Francisco María Tubino y el movimiento cervantista del siglo XIX. Madrid.

Kultermann, U. 1996: Historia de la Historia del Arte. El camino de una ciencia. Madrid.

Madrazo y Kuntz, P. de 1884: Sevilla y Cádiz. Madrid

Manzano Martos, R. 1995: “Casas y Palacios en la Sevilla Almohade. Sus precedentes hispánicos", en Navarro Palazón, J. (ed.), Casas y palacios de Al-Andalus: (siglos XII y XIII). Barcelona, pp. 315-352.

Manzano Martos, R. 1999: Prólogo a Tubino y Oliva, F. M.: El Alcázar de Sevilla. Sevilla.

Marín Fidalgo, A. 1990: El Alcázar de Sevilla bajo los Austrias. Sevilla

Moreno Martín, F. J. 2014: "Arqueología de la Arquitectura. Una visión conciliadora desde la Historia del Arte", Arqueología de la Arquitectura, 11: e009.

Muñoz Pérez, A. 1988: "Tubino: Apuntes para una biografía”, Almoraima. Revista de Estudios Campogibraltareños, 0, 81-84.

Peiró Martín I. y Pasamar Alzuria G. 1991: “El nacimiento en España de la Arqueología y la Prehistoria (Academicismo y profesionalización, 18561936)", Kalathos, 9-10, pp. 9-30.

Pierotti, P. y Quirós, J. A. 2000: “Archeologia dell'architettura e storia dell'architettura: due discipline a confronto", en Brogiolo, G. P. (ed.), II Congresso Nazionale di Archeologia Medievale. Musei Civici, Chiesa di Santa Giulia. Brescia, 28 settembre-1 ottobre 2000, pp. 377-380. All'Insegna del giglio, Florencia.

Portús, J. 2015: "La historiografía artística: las artes plásticas”, en Aullón de Haro, P. (coord.), Historiografia y teoría de la historia del pensamiento, la literatura y el arte. Madrid.

Quirós Castillo, J. A. 2002: “Arqueología de la Arquitectura en España”, Arqueología de la Arquitectura, 1, pp. 27-38.

Revuelta Tubino, M. 1989: "Un académico olvidado: Francisco María Tubino, a los cien años de su muerte (1833-1888)", ACADEMIA. Boletín de la Real Academia de Bellas Artes de San Fernando, 68, pp. 61-101.

Ripoll López, O. y Ripoll López, G. 1988: "Los conceptos de arqueología e historia del arte antiguo y medieval: apuntes historiográficos", Espacio, Tiempo y Forma, Serie II, Historia Antigua, t. I, 1988, pp. 411-426

Rueda Muñoz de San Pedro, G. 1991: "Franciso M." Tubino (1833-1888) y la Revista de Bellas Artes (1866-1968)", en J. Arce y R. Olmos (eds.). Historiografia de la Arqueología y de la Historia Antigua en España (XVIII-XX). Madrid.

Tabales Rodríguez, M. A. 1997-1999: Intervención arqueológica en el Patio de la Montería del Real Alcázar de Sevilla. Memoria cientifica. Sevilla.

Tabales Rodríguez, M. A. 2002a: El Alcázar de Sevilla. Primeros estudios sobre estratigrafia y evolución constructiva. Sevilla.

Tabales Rodríguez, M. A. 2002b: "Investigaciones en la primitiva puerta del Alcázar de Sevilla”. Anuario de Arqueología Andaluza 1999, pp. 195-211. Sevilla.

Tabales Rodríguez, M. A. 2006: "Investigaciones arqueológicas en la portada de la Montería”, en Apuntes de Alcázar de Sevilla, 7, pp. 7-39.

Tabales Rodríguez, M. A. 2010: El Alcázar de Sevilla. Reflexiones sobre su origen y evolución en la Edad Media. Memoria arqueológica 2000-2005. Sevilla.

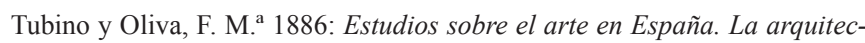
tura hispano-visigoda y árabe española. El Alcázar de Sevilla. Una iglesia mozárabe. Sevilla.

Tubino y Oliva, F. M. 2003: Historia del Renacimiento literario contemporáneo en Cataluña, Baleares y Valencia, P. Anguera (ed.). Pamplona. 